\title{
ARTICLE
}

\section{In defence of professional judgement ${ }^{\dagger}$}

\author{
Robin Downie \& Jane Macnaughton
}

\begin{abstract}
Robin Downie is Emeritus Professor of Moral Philosophy at Glasgow University. His interests include the philosophy of medicine, medical ethics and using the humanities in medical education. His most recent book (with Jane Macnaughton) is Bioethics and the Humanities: Attitudes and Perceptions. Jane Macnaughton is Director of the Centre for Arts and Humanities in Health and Medicine at Durham University. Her research interests include medical humanities, professionalism in undergraduate medical education and arts in health. She has published two books with Robin Downie, including Clinical Judgement: Evidence in Practice.

Correspondence Robin Downie, Emeritus Professor of Moral Philosophy, University of Glasgow, Glasgow G12 800, UK. Email:
\end{abstract} r.downie@philosophy.arts.gla.ac.uk

${ }^{\dagger}$ For a commentary on this article see pp. 328-331, this issue.

\section{SUMMARY}

A judgement may be defined as an assertion made with evidence or good reason in a context of uncertainty. In psychiatry the uncertainty is inherent in the professional context and the evidence derives from academic literature and scientific studies as they are applied to a specific patient. The nature of the uncertainty and the factors that should inform professional judgement are explored in this article. Professional judgement currently faces two serious challenges: an obsession with numbers, which comes from within medicine, and the 'patient choice' agenda, which is politically inspired and comes from outside medicine. In this article we strive to defend professional judgement in the clinic against both challenges.

\section{DECLARATION OF INTEREST}

None.

The 18th-century philosopher Thomas Reid defined a judgement as an assertion made with some evidence, or for a good reason, in a context of uncertainty (Reid 1975 reprint). There can of course be bad judgements when the evidence is defective. For simplicity, we shall use 'judgement' to refer to good judgement. There are two basic types of (good) judgement: theoretical and practical. A theoretical judgement is an assertion about what is probably true or correct, and a practical judgement concerns what we ought to do. In both cases there must be some evidence or reasonable considerations determining our judgement, otherwise it is not a judgement but a guess. In both cases the context must be one of uncertainty. We do not judge that $2+2=4$ because we know it with certainty. Theoretical and practical judgements are of course often linked in that our judgement of what we have good evidence for believing can be grounds for our judgement of what we ought to do.

A professional judgement is a judgement made in a professional context. It can be either theoretical or practical. More explicitly, the uncertainty derives from the professional context and the evidence or relevant considerations are acquired by means of professional knowledge and skills. We shall first explore the professional context that gives rise to the uncertainty and then suggest factors that should inform professional judgement. It will emerge from this analysis why professional judgement is worth defending against some current threats to it.

\section{Factors that create uncertainty in the professional context}

Several factors can create uncertainty for healthcare professionals. First, there can be uncertainty concerning diagnosis. This is notoriously the case with mental illness. Second, even when the diagnosis is reasonably clear there can be uncertainty about how long the illness will last and whether it will give rise to any complications. Third, there can be uncertainty about the treatment. The evidence might suggest that it will lead to an improvement in $65 \%$ of patients, but will it benefit this patient? Fourth, the patient may be uncertain. Patients are, by the nature of their situation, in a weak position and a psychiatrist's patients are among the most vulnerable of all. They may be confused, hostile to the psychiatrist and resistant to all treatment, or reserved and uncommunicative. Uncertainty about how to proceed is inevitable. These four types of uncertainty (there may be others) can be summed up by saying that in all medical situations there is likely to be a varying degree of uncertainty about what is in the patient's best interests and that this uncertainty is at its maximum with patients with psychiatric disorders. The first condition for professional judgement - uncertainty - is therefore manifestly present with patients under psychiatric care.

\section{Factors that should determine professional judgement in psychiatry}

\section{Theoretical factors}

The primary theoretical factor is obviously the long training in medical school and thereafter the specialised training required by the medical Royal Colleges and other institutional bodies concerned with the making of the competent consultant. Despite the emphasis on the academic side of medical training, it remains importantly a kind of apprenticeship based on the model of 'see one, do one, teach one'. Bedside teaching remains of the first 
importance for informing the judgement of trainee psychiatrists. This may be especially true for the art of diagnosis.

Trial-based evidence should also inform the judgement of the psychiatrist. Evidence-based medicine (EBM) has for many years been a widely accepted slogan and all branches of medicine insist on continuing medical education (CME) (or continuing professional development, $\mathrm{CPD}$, as it is usually known in UK psychiatry), where the latest evidence-based treatments are discussed. There can be no doubt that technical knowledge deriving from EBM must be dominant among the factors that determine theoretical judgements in psychiatry.

\section{Practical factors}

Practical judgements will have EBM as a central component. But EBM is by no means the only relevant factor which should determine practical judgement. Doctors must also know when, how and how much to exercise their skills. For example, what is the balance of benefits to harms and risks? Does the patient really understand these? Has the patient consented to the risks? What are the longterm prospects of recovery? This kind of judgement is of a different order from diagnostic and treatment judgements; it certainly involves technical judgements, but it also involves judgements of (broadly speaking) moral value. Judgements of this kind are unique to medicine and to understand their importance we need to consider the special relationship that the psychiatrist has with a patient. It is in this special relationship that we shall find the third and fourth factors that should inform professional judgement in psychiatry.

\section{Relationships: bonds}

The word 'relationship' can be used in two ways (Downie 2000: pp. 78-89). It can refer to the bonds that hold two people together or it can refer to their attitudes to each other. For example, if we see two people together, we might enquire as to their relationship and receive answers such as father and son, colleagues, husband and wife, teacher and pupil, doctor and patient, and so on. To characterise a relationship in this way is to ask about what we are calling 'bonds'. But we might ask what kind of relationship do Bloggs and his son have and be told 'Bloggs has great affection for his son, but his son has nothing but contempt for his father'. Or we might say of a husband and wife that their relationship is deteriorating, or of a doctor and a patient that the patient trusts the doctor and the doctor respects the patient. Answers of that kind characterise a relationship in terms of attitudes. A professional relationship requires both bond and attitude.
The bonds in a professional relationship are decided by the governing body, for example, by the General Medical Council. Special bonds are necessary between professional and patient because of the inequality in the relationship. In brief, the client or patient is vulnerable and needs the protection of the bond. In general, we might say that the bond takes the form of a role relationship, in which both professional and client have rights and duties laid down by the governing body. For example, to offer the service a doctor might need to know various intimate details about the patient. The patient must be reassured that no untoward use will be made of this information. Hence, the duties of confidentiality are imposed on the professional. Doctors are told that 'the patient is a person' and so on. Yes, but patients are also in a role relationship when they are dealing with a professional. The nature of the role is laid down by the professional body and obviously reflects the values of the profession. In other words, ethics enters a profession via the professional bond.

The third factor that should inform professional judgement in psychiatry is therefore knowledge of the legal and ethical regulations that exist in legislation and in guidance from the medical Royal Colleges, the British Medical Association and the General Medical Council. Obtaining informed consent for treatment is especially problematic in psychiatry when questions of the patient's competence to consent may be doubtful, and in England the Mental Capacity Act 2005 has altered the situation. Hence, knowledge of current regulations is an important determinant of professional judgement.

\section{Relationships: attitudes}

The fourth factor, professional attitude, must reflect awareness of the vulnerability of the client or patient. Often the professional attitude is described by a phrase such as 'concern for best interests'. It is the doctor's duty to supply information to the patient and the patient's right to give or withhold consent to the proposed treatment in the light of that information. Whatever the details of the appropriate attitudes involved in the professional relationship - and we shall say more on this - an attitudinal component is the fourth factor that should inform professional judgement. Indeed, in psychiatry the attitude of the psychiatrist to the patient may be integral to the healing process.

\section{Developing professional judgement}

How can the four factors we have mentioned as necessary for informing judgement in psychiatry be developed? There is little difficulty about the first two. As we noted, diagnostic skills can be 
acquired in various ways but apprenticeship may be the most important way. Information on appropriate treatments can be obtained from the copious literature and databases. Ethics also can be presented in a teachable and learnable way. Sometimes it is said that ethics is entirely a matter of opinion. As far as medicine goes this view is false. The British Medical Association, General Medical Council, medical Royal Colleges (and similar institutions in other countries) issue guidelines on ethical issues and these represent current ethical thinking. Doctors can and ought to be familiar with these quasi-legal documents if they are to make informed and acceptable treatment judgements.

\section{The attitudinal factor}

It is much harder to develop what we have called the attitudinal factor in judgement. We might suggest that whereas the first three factors determining good judgement require expert training, the attitudinal component requires a broad education. What are the differences between being trained to have skills and being educated in humane values? This, of course, is a large topic in its own right but a few points can helpfully be made here (Downie 2007).

First, the person educated in humane values has a broad cognitive perspective and can see the significance of medicine in a total way of life. Second, the person with humane education has continual curiosity about the world, a desire to develop knowledge and skills throughout a working life, and is aware of the standards of work that must be satisfied. Here we have the familiar idea of a 'professional job' or 'a job well done'. Third, the idea of a humane education embodies the idea of ethics. It is possible to be trained to pick pockets, as in Dickens' Oliver Twist, but a humane education is necessarily directed to socially worthwhile ends. Here we have the idea of standards of behaviour, of 'being professional' in one's approach to a client or patient. Fourth, the broadly educated person has a flexibility of mind that enables things to be seen in a variety of ways. To paraphrase the words of the educational philosopher R.S. Peters (1967: p. 8): to be trained is to have arrived, but to be educated is to travel with a different view. Good judgement requires the constant review of false finalities.

We shall not take up the question of how far undergraduate medical schools or postgraduate continuing medical education stress or concern themselves at all with broad education in humane values. Professionalism has for some time in the USA been linked to the growing field of "medical humanities" ${ }^{\dagger}$ and this link is now also becoming apparent in the UK (Meakin 2007). This connection offers the opportunity to broaden medical training into medical education and thereby develop the insights of professional judgement.

\section{Challenges to professional judgement}

There are various contemporary challenges to professional judgement. We shall discuss two: that the need for professional judgement is minimised by stressing the alleged 'objectivity' of quantitative data; and prioritising patient choice over professional judgement.

\section{The distorting effect of numbers}

Research in psychiatry is of various kinds, but we shall confine our discussion to qualitative research (Jones 1995). Qualitative research is concerned with such matters as what a disease or a treatment 'means' to a patient ('patient-centredness') or 'doctor satisfaction'. Issues of this kind are important because they provide knowledge on which clinical judgement can be based. However, if knowledge or evidence is to be useful for informing clinical judgement as it applies to a variety of individual patients, it must in some way be generalisable. How can what is essentially qualitative be generalised?

\section{The quantification of qualities}

In quantitative research, generalised knowledge is acquired via inductive procedures. For example, a cohort of patients with a given disorder and other similarities may be selected for a new treatment and others for a placebo or an existing treatment. The new treatment may be shown to have some success with $70 \%$ of patients in the cohort. This generalised evidence is then available to inform the clinician's judgement concerning an individual patient. The use of numbers and the procedures of randomisation suggest that the evidence is 'objective', and can therefore be relied on as a basis for judgement for an individual patient.

In view of the need to generalise and so acquire objectivity there has been a tendency to force qualitative research into a similar quantitative mould. For example, we find qualities such as patientcentredness being given a score of 1.45 and doctor satisfaction measured as 8.95 (Law 1995). We have discussed in detail elsewhere the wider issue of whether qualitative research can meaningfully use measurements and scales in the manner of quantitative research and will not repeat the arguments here (Downie 2000: pp. 26-38). We shall argue here that the attempt to generalise and achieve 'objectivity' via numbers actually distorts the way doctors view their patients and therefore distorts their clinical judgements. Finally, we shall suggest another way to interpret qualitative research that has a different kind of connection with judgement. 


\section{Reductionism}

The single most important factor that leads to the distortion of qualitative research and therefore the judgements based on it we can call 'reductionism'. The term is used in a variety of ways (Honderich 2005) but we mean here the process of seeing human beings and their interactions in terms of a number of discrete features. Reductionism is essential for countability because there must be an answer to the question: what are you counting? In qualitative research those features are (for example) eye contacts or answers to questions in the form of ticks in a box. But to try to understand patients in this way, in terms of a finite number of discrete features, is to abstract from the complexity and totality of a human interaction. Blood pressure can helpfully be abstracted in this way and measured, but not a human response in its complex totality. There is something not only patronising but clinically misleading in the suggestion that the complexity of human relationships can be reduced to a few factors and 'measured' with an 'assessment tool'.

The desire to use numbers (because they are thought to be 'objective') has a distorting effect in two ways. First, the use of numbers suggests that the knowledge obtained by the qualitative research is a kind of induction-based knowledge when (as we shall see) it is quite different in nature and has a different sort of bearing on individual judgement. Second, the application of that knowledge to particular patients has replaced what should be individualised judgement with the mass use of questionnaires, or 'assessment tools'. Medical training rightly stresses the importance of listening skills. On the other hand, the reality is that rather than listen to what the patient may be saying, the doctor or nurse presents the patient with a form to fill in and boxes to tick (Randall 2006). This is done on the grounds that such a procedure utilises countable results that are therefore more 'objective' than simply having a discussion with the patient. It certainly attempts to minimise clinical judgement.

It should also be noted that if the underlying purpose of questionnaires and measurement scales is to avoid the need for judgement then they fail. Judgement is required to decide what questions to ask, what numbers to assign to them and how to interpret the final scores. Judgements can be dangerous when the professionals are unaware they are making them and believe themselves to be objective.

\section{Generalisability and qualitative research: a different route to judgement}

If the knowledge obtained by qualitative research is to be useful in informing professional judgement, how should it be viewed? The answer is that the lessons of qualitative research for clinicians are derived from considering the plausibility of the particular situation in terms of their own experience, and on finding parallels that are helpful. The question for the reader of qualitative research is: are there any general features in this situation that I recognise and can apply? The understanding involved in qualitative research is more akin to the understanding gained from literature and art than that gained from a numerical science. This does not mean that it is an inferior kind of understanding, but it does mean that it is different in that it is reached by a different route and informs judgement in a different way. It requires the active participation of readers to identify with the situation and relate the findings to their own situations. In reaching this understanding, the life experience and maturity of clinicians are all-important.

\section{Identification with the situation}

Consider the following example. Sartre (1943) describes a man bending down to listen at a keyhole. He believes that his wife is in the next room with her lover. Suddenly, he hears a step behind him and immediately his attitude changes. To begin with, he wanted to hear a conversation, but now he has become an object to someone else - an eavesdropper to be described and despised. This example shows how moral emotions, such as shame, are experienced in a social context. The eavesdropper minds being caught because he must now think of himself as mean and sneaky. He despises such characteristics in others and now he must despise himself.

We have used this example because it is similar to many in qualitative medical research. The route to understanding is through our identification with the situation. Through that identification we reach general features of human emotions. There is an element of generalisation, but not by induction. The imposition of quantitative language would obstruct this understanding by distorting the findings of qualitative research and making them obscure to the reader. Even if the approach of such research is narrative and descriptive of particular situations, for the mature clinician it can still provide understanding of general features of clinical situations that can inform judgement concerning individual patients.

\section{The illumination of language}

Qualitative researchers take pride in the fact that their approach provides new insight into clinical situations. They should not hide these insights under a numerical bushel but illuminate them with language that reflects the new kind of understanding they wish to convey. To attempt to put numbers to 
the research is to distort both it and the relationship between doctor and patient that it is attempting to illuminate. Qualitative research is best interpreted by analogy with the humanities. By identifying with a particular situation, the researcher or clinician can recognise the general elements in human emotion. This is unlike the generalisability of inductive science. It requires a moral maturity in the doctor and it can lead to a humane understanding of the patient, which in turn will produce a humane judgement.

It might be objected that our arguments assume a universality in human emotions that may not exist, especially with patients with psychiatric disorders. But even if there is no universality in human emotions and reactions, there is a broad similarity and that may be all that is needed as a basis for individualised judgement. After all, even in genuine quantitative research a success rate of $70 \%$ might be thought significant.

\section{Patient choice}

'Patient choice' is a Trojan horse in the sense that it suggests the desirable involvement of the patient in treatment decisions. Of course, 'patient choice' also emphasises the right of the patient to refuse treatments, for whatever reason (General Medical Council 2008). The problem is, however, that patient choice has now come to mean consumer choice, something very different from the choice or refusal of treatments offered by the doctor (Bate 2005). Consumers'judgements and choices of the products they want trump those of the sales assistant. If patients are consumers should their judgements and choices trump those of the professional?

What are the conditions of consumer choice? We have discussed the general conditions for consumerism and its threat to the National Health Service (NHS) elsewhere (Downie 2008) and will not repeat the arguments here. The threat specifically to professional judgement comes from two conditions of the free market: that the consumer can determine the options available for choice, and that the consumer must take responsibility for what is chosen. For example, if the shop does not have the goods desired then the consumer can turn to the internet and bears responsibility for goods so chosen. Let us examine the impact of these conditions on professional judgement.

\begin{tabular}{|c|c|c|c|c|}
\hline \multicolumn{5}{|c|}{ MCO answers } \\
\hline 1 & 2 & 3 & 4 & 5 \\
\hline a & af & $a f$ & $a f$ & af \\
\hline & $b f$ & $b f$ & $b f$ & $b f$ \\
\hline & $c f$ & $c f$ & $c f$ & $\mathrm{ct}$ \\
\hline & $d f$ & $d t$ & $d f$ & $d f$ \\
\hline & et & ef & e t & ef \\
\hline
\end{tabular}

\section{Consent}

First, in the traditional model the doctor offers only those options judged to provide net benefit and the patient consents to or refuses what the doctor offers. In contrast, in the consumer model the patient requires the doctor to provide what the patient judges to be effective. Thus, the patient is not consenting to the treatment but authorising the doctor to carry it out. The doctor has become merely the agent of the patient. It might be argued that the doctor could conscientiously object to carrying out a treatment that the patient requests if the doctor judges that it is inappropriate. But note the extraordinary paradox: in this situation the doctor has become the one who consents or refuses and the patient the one who makes the judgement. In short, professional judgement in its true sense is bypassed.

\section{Locus of responsibility}

The second condition of consumer choice concerns the locus of responsibility. In the consumer choice model, the consumer takes full responsibility for the choice. In contrast, in the traditional model of choice and consent, the doctor takes responsibility for judging which options should be offered to the patient, while the patient takes responsibility for consenting to or refusing what was offered. The traditional model of choice could justifiably be described as joint responsibility, since each party has responsibility for different aspects of the decision. By contrast, if consumer choice were accepted in the NHS then, logically, the responsibility must pass entirely to the patient and the need for professional judgement would be much diminished.

\section{Professional judgement and consumerism: some implications}

What would a true consumerist healthcare system be like? It would have at least two implications of major importance for the whole concept of medicine as a profession and therefore for professional judgement.

First, the concept of a profession would alter. A doctor or nurse would become simply a purveyor of goods and services, like a plumber, a garage mechanic or a shop assistant. A doctor would not be required to have the values of the profession or to exercise professional judgement. For example, the Royal College of Physicians' document on professionalism (2005) expects doctors to have the qualities of compassion, integrity, altruism, etc. But these qualities do not feature in the consumer choice model and indeed they are out of place there. Consumerism has ethics and responsibilities, but they are quite different from those of professionalism.

Second, consumer choice in the NHS would lead to a change in motivation among the professionals. In the consumer choice model, the provider of the service is motivated less by a desire to improve the overall welfare of the consumer than to provide goods and services that will satisfy the consumer's 
requirements at the lowest possible cost to the provider, thus achieving a financially acceptable profit margin. Indeed, the situation is worse than that. Trust is the foundation of the doctor-patient relationship and patients still believe that their psychiatrist is uniquely concerned with their health. There is a reasonable fear that consumerism in the NHS will weaken the unique trust that patients must be able to place in their doctors, destroy the idea of professional judgement and indeed destroy the whole idea of medicine as a profession.

\section{Conclusions}

Diagnostic and treatment uncertainties are inherent in psychiatry, thus putting a premium on clinical judgement. The use of numbers can sometimes assist judgement, but can never determine it completely, because judgement is required to interpret numbers and decide what they mean for a given patient. Moreover, in qualitative research the use of numbers (employed to give the semblance of scientific objectivity) can actually obscure its insights. Such insights are more helpfully interpreted as analogous to those obtained from literature. Patient choice can lead to desirable joint decision-making, but if patient choice trumps professional judgement then the whole idea of psychiatry as a profession must be abandoned. Psychiatrists must hold on to clinical judgement informed by real science and educated in humane values.

\section{References}

Bate P, Robert G (2005) Choice. BMJ; 331: 1488-9.

Downie R, Macnaughton J (2000) Clinical Judgement. Evidence in Practice. Oxford University Press: 78-89.

Downie R, Macnaughton J (2007) Bioethics and the Humanities. Attitudes and Perceptions. Routledge-Cavendish: 117-20.

Downie R, Randall F (2008) Choice and responsibility in the NHS. Clinical Medicine; 8: 182-5.

General Medical Council (2008) Consent: Patients and Doctors Making Decisions Together. GMC

Honderich T (ed) (2005) The Oxford Companion to Philosophy. Oxford University Press.

Jones $\mathrm{R}$ (1995) Why do qualitative research? BMJ; 45: 131-2

Law S, Britten N (1995) Factors that affect the patient-centredness of a consultation. British Journal of General Practice; 45: 520-4.

Meakin R (2007) Teaching medical students professionalism. What role for the medical humanities? Journal of Medical Ethics: Medical Humanities; 33: 105

Peters R (1967) The Concept of Education. Routledge \& Kegan Paul.

Randall F, Downie R (2006) The Philosophy of Palliative Care. Critique and Reconstruction. Oxford University Press: 35-44.

Reid T (1975 reprint) Thomas Reid's Inquiry and Essays (eds K Lehrer, R Beanblossom). Bobbs-Merril.

Royal College of Physicians (2005) Doctors in Society. Medical Professionalism in a Changing World. Report of a Working Party. Royal College of Physicians.

Sartre J-P (1943) Being and Nothingness (trans H Barnes). Methuen.

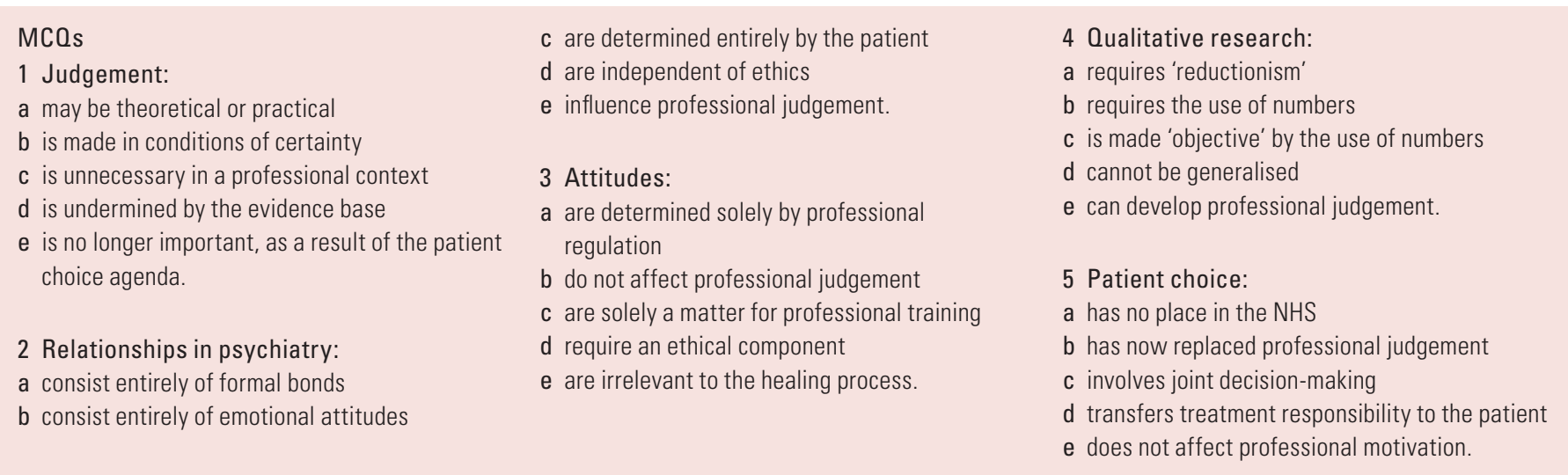

